\title{
ATUAÇÃO DA ENFERMAGEM FRENTE À SEXUALIDADE DO IDOSO NO CONTEXTO FAMILIAR: UMA REVISÃO INTEGRATIVA
}

\author{
NURSING ACTING AGAINST THE SEXUALITY OF THE ELDERLY IN \\ THE FAMILY CONTEXT: AN INTEGRATING REVIEW
}

Amauri dos Santos Araujo ${ }^{1}$ Izadora Nunes da Silva ${ }^{2}$

Glaucia dos Santos Silva ${ }^{3}$ Vanessa Maria do Nascimento ${ }^{4}$

RESUMO: O envelhecimento é um processo que afeta todos os indivíduos, assim os idosos, tornam-se cada vez mais dependentes dos familiares, e o cuidado da enfermagem ao idoso. OBJETIVO: identificar a atuação do enfermeiro frente à sexualidade do idoso no contexto familiar. MÉTODOS: trata-se de um estudo de Revisão Integrativa da literatura que tem como caráter quantitativo e descritivo, realizado através da base de dados da Biblioteca Virtual em Saúde no recorte temporal de 2013 a 2018. RESULTADOS E DISCUSSÕES: as seleções dos artigos ocorreram a partir do refinamento realizado com os critérios de inclusão e da leitura dos títulos, dos resumos, das disponibilidades na íntegra e gratuita e da leitura completa dos estudos. É de suma importância a qualificação, especialização do profissional enfermeiro na área de geriatria $e$ na gerontologia para 0 acompanhamento aos pacientes idosos e familiares, pois, a enfermagem que irá treinar, educar, supervisionar, auxiliar quanto ao processo do cuidado no envelhecimento, ajudando tais com medidas e respondendo questionamentos sobre o corpo, desejos sexuais, compreensão das adaptações, que tornam necessárias para as resposta sobre a sexualidade e também no âmbito familiar. CONCLUSÃO: o enfermeiro tem o papel indispensável nesse processo, pois está ligado diretamente aos pacientes idosos, com isso, podendo-se promover os esclarecimentos sobre essa temática, além da quebra de crenças e tabus estabelecidas pela sociedade.

Palavras chave: Enfermagem. Família. Idoso. Sexualidade.

\footnotetext{
${ }^{1}$ Enfermeiro. Mestrando em enfermagem pelo PPGENF/EENF/UFAL. Professor da Faculdade de Tecnologia de Alagoas. E-mail: amauriaraujo.sms@gmail.com.

${ }^{2}$ Graduanda em Enfermagem pela Faculdade de Tecnologia de Alagoas.

${ }^{3}$ Graduanda em Enfermagem pela Faculdade de Tecnologia de Alagoas.

${ }^{4}$ Graduanda em Enfermagem pela Faculdade de Tecnologia de Alagoas.
} 
ABSTRACT: Aging is a process that affects all individuals, so the elderly become increasingly dependent on family members, and nursing care to the elderly. OBJECTIVE: to identify the nurse's performance regarding the elderly's sexuality in the family context. METHOD: this is an integrative literature review study that has a quantitative and descriptive character, conducted through the database of the Virtual Health Library in the time frame from 2013 to 2018. RESULTS AND DISCUSSIONS: the selection of articles occurred from the refinement performed with the inclusion criteria and the reading of titles, abstracts, full and free availability and full reading of the studies. It is extremely important the qualification, specialization of the professional nurse in the area of geriatrics and gerontology to accompany the elderly and family patients, because the nursing that will train, educate, supervise, assist in the process of care in aging, helping such with measures and answering questions about the body, sexual desires, understanding of the adaptations that make it necessary for the answers about sexuality and also in the family context. CONCLUSION: the nurse has the indispensable role in this process, as it is directly linked to the elderly patients, with this, being able to promote the clarification on this theme, besides the breaking of beliefs and taboos established by the society.

Keywords: Nursing. Family. Old man. Sexuality. 


\section{INTRODUÇÃO}

O envelhecimento é um processo multidirecional, gradual e irreversível e é mais do que a soma do tempo que passa. Gonçalves (2015) reitera que é um fenômeno complexo, que engloba simultaneamente aspectos fisiológicos, psicológicos e sociais; geralmente considera- se que o envelhecimento ocorre ao longo do ciclo de vida e que a velhice corresponde ao seu estágio final da vida.

Portanto é uma fase em que, ponderando sobre a própria existência, o indivíduo idoso conclui que alcançou seus objetivos, mas também sofreu perdas, destacando-se na realidade a condição de saúde como um dos aspectos mais afetados (VALCARENGHI et al., 2015).

O surgimento da velhice é rodeado de visões estigmatizadas e equivocadas, que representam tabus não só para a população e família, como também para profissionais de saúde que nem sempre levam em consideração em seus atendimentos a vida sexual dos (FERRO et al., 2016).

$\mathrm{Na}$ atualidade a sexualidade é um tema que exige cuidado ao ser abordado em decorrência de ser uma temática peculiar e por possuir uma gama de significados ancorada a uma infinidade de fatores. Destarte, pode ser definida como energia que nos conduz a procurar amor, contato, ternura e intimidade; logo se integra no estado, sentimentos, movimentos e toques. Portanto trata-se de uma expressão fulcral da vida do ser humano que compreende o sexo, identidade, gênero, orientação sexual, erotismo, prazer, intimidade e reprodução (MARQUES et al., 2015).

Com esta percepção nota-se a participação da pessoa idosa na comunidade, e na convivência social, bem como surge no contexto às políticas públicas, como componente essencial para um envelhecimento ativo e saudável. Assim, nota-se que a solidão e a falta de apoio social além de serem um problema conhecido na velhice também são fatores de risco importantes para a depressão nessa faixa (ROMERO et al., 2019). 
Assim sendo, considerado que a família é a primeira instituição que oferece cuidado ao idoso em situação de dependência, é fonte de suporte, tem como principais motivos a obrigação moral, o vínculo afetivo e os laços sanguíneos e consanguíneos (MOCELIN et al., 2017).

$\mathrm{Na}$ realidade, mostra-se que a maior parte da responsabilidade com o idoso ainda recai sobre a família, normalmente sobre o membro do gênero feminino, que se torna cuidador informal e que não recebe orientações, nem possui uma estrutura eficaz para prestar cuidados efetivos ao idoso (MIRANDA et al, 2015). Frente a este contexto, surge a seguinte questão norteadora: qual o papel do enfermeiro, frente a sexualidade do idoso no contexto familiar? Sendo assim, esse estudo tem como objetivo, identificar a atuação do enfermeiro frente à sexualidade do idoso no contexto familiar.

\section{METODOLOGIA}

Trata-se de um estudo de revisão integrativa; permitindo deste modo, a síntese de trabalhos para a realização de uma ampla abordagem metodológica referente a revisões, partindo da inclusão de estudos experimentais e não experimentais para uma compreensão completa do fenômeno analisado (ARAUJO et al., 2018; SOUZA; SILVA; CARVALHO, 2010; WHITTEMORE; KNAFL, 2005).

Para este tipo de estudo, faz-se necessário percorrer seis etapas distintas: identificação do tema e seleção da hipótese ou questão de pesquisa; estabelecimento de critérios para inclusão e exclusão de estudos/amostragem ou busca na literatura; definição das informações a serem extraídas dos estudos selecionados/ categorização dos estudos; avaliação dos estudos incluídos na revisão integrativa; interpretação dos resultados; Apresentação da revisão/síntese do conhecimento (ARAUJO et al., 2018; MEDEIROS; PAIXÃO; MIRANDA, 2017; SOUZA; SILVA; CARVALHO, 2010; WHITTEMORE; KNAFL, 2005; SOUZA).

Deste modo, a coleta de dados deu-se através da base de dados da Biblioteca Virtual em Saúde (BVS), no período de agosto a setembro de 2019, em 
duas etapas, a primeira constitui na identificação dos Descritores em Ciências da Saúde (DeCS), e a segunda, ocorreu a partir do cruzamento: "sexualidade", "idoso", "família" e "enfermagem", por meio do formulário próprio da base de dados, com a combinação do booleano AND.

A Figura 1 tem por finalidade apresentar os resultados obtidos a partir do cruzamento dos DeCS com o booleano AND: "sexualidade" AND "idoso" AND "família". Logo, foram localizados 120 artigos, destes, 08 atenderam aos critérios de inclusão. A figura 2 apresenta os resultados obtidos a partir do cruzamento dos DeCS: "sexualidade" AND "idoso" AND "enfermagem", ao qual foram encontrados 196 artigos e 03 (três) destes foram selecionados, resultando em uma amostra final de 11 artigos.

Para este refinamento foram adotados os seguintes critérios de inclusão: artigos científicos com ano de publicação no recorte temporal de 2013 a 2018; artigos nacionais e disponibilizados na íntegra e gratuitamente e que apresente um dos autores como profissional enfermeiro/a. Foram adotados como critérios de exclusão: teses, monografias, dissertações e textos não científicos e que estivessem com problemas no acesso ao artigo indexado nas bases de dados selecionadas para construção do estudo científico.

Figura 01 - Processo de seleção dos artigos após leitura integral dos estudos Brasil, 2019.

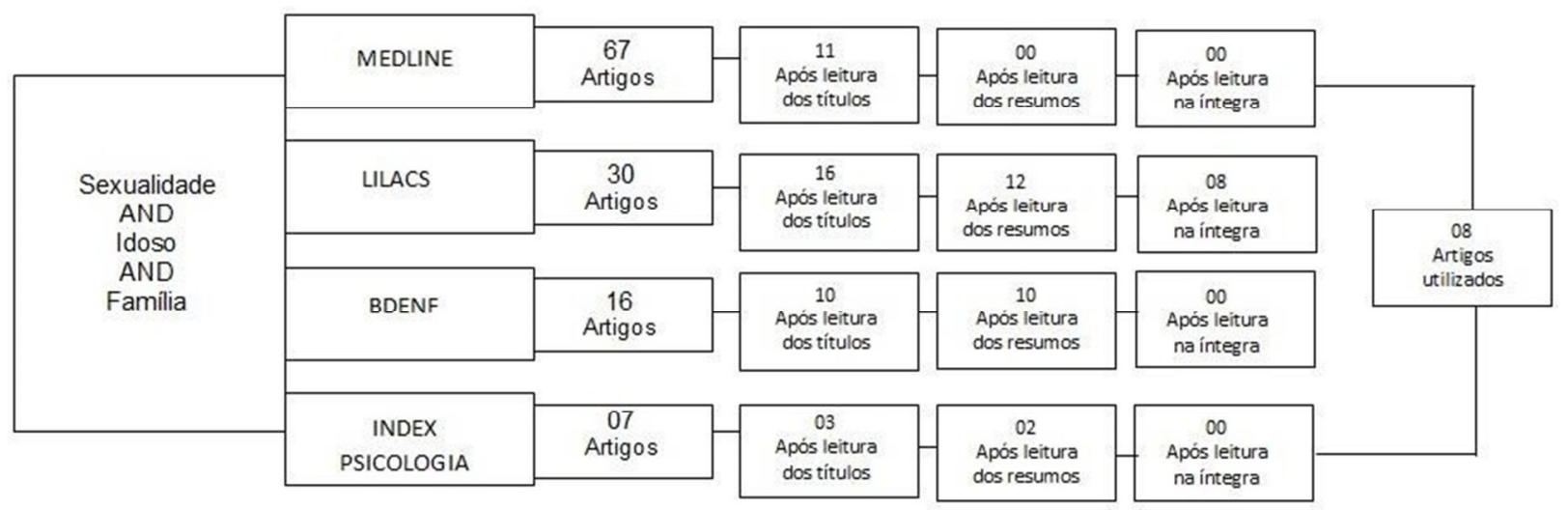

Fonte: elaborado pelos autores, 2019. 
Figura 02 - Processo de seleção dos artigos após leitura integral do estudo - Brasil, 2019.

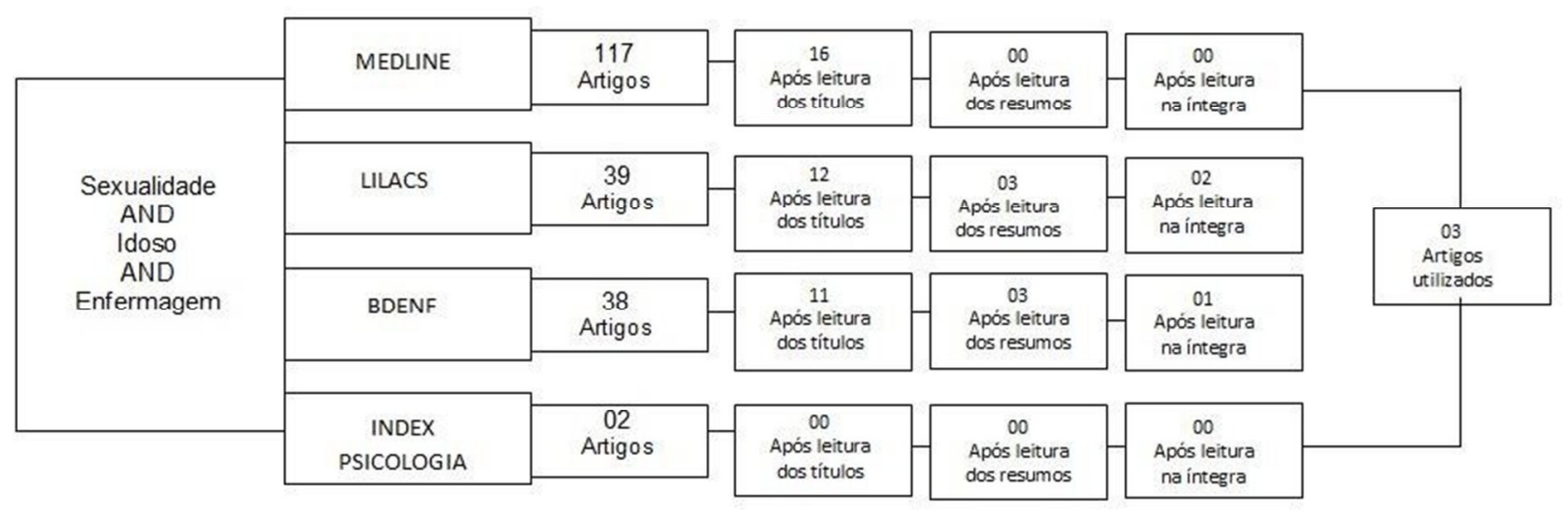

Fonte: elaborado pelos autores, 2019.

\section{RESULTADOS E DISCUSSÕES}

A seleção dos artigos ocorreu a partir do refinamento realizado com os critérios de inclusão e da leitura dos títulos, dos resumos, das disponibilidades na íntegra e gratuita e da leitura completa dos estudos. Deste modo, a distribuição dos estudos selecionados para composição da amostra, apresenta resultados significativos para meio científico segundo o ano de publicação. Representando maior número de publicações nos anos de 2015 , com $45,45 \%$ e 2017 , com $18,18 \%$. Nos anos de 2016, 2018 e 2019, apresentam (9,09\%) respectivamente, conforme exposto na Tabela 1. 
Tabela 1 - Distribuição da amostra por ano de publicação, idioma de publicação e base de dados indexação - Maceió, AL, Brasil, 2019.

\begin{tabular}{ccc}
\hline Ano de Publicação & Base de Indexação & Quantitativo \\
\hline $\mathbf{2 0 1 5}$ & LILACS & 05 \\
$\mathbf{2 0 1 6}$ & BDENF & 01 \\
$\mathbf{2 0 1 7}$ & LILACS & 01 \\
$\mathbf{2 0 1 8}$ & LILACS & 02 \\
$\mathbf{2 0 1 9}$ & LILACS & 01 \\
& LILACS & 01 \\
\hline
\end{tabular}

Fonte: elaborado pelos autores, 2019.

Os estudos foram distribuídos de acordo com a caracterização do Quadro 1, quanto ao título, base de dados, ano de publicação, objetivo, tipo de estudo e síntese do estudo. Onde após a análise dos estudos foram encontradas particularidades específicas entre os artigos, onde de um modo geral os estudos selecionados mostram desde os fatores que interferem no processo da sexualidade, a percepção do idoso em relação a essa temática e a atuação do enfermeiro no processo de sexualidade do idoso no contexto familiar.

Quadro 1 - Síntese dos estudos sobre "A atuação do enfermeiro no processo de sexualidade do Idoso no contexto familiar: uma revisão integrativa"- Maceió, AL, Brasil, 2019.

\begin{tabular}{|c|c|c|c|c|c|}
\hline $\begin{array}{l}\text { TíTULO DO } \\
\text { ARTIGO }\end{array}$ & $\begin{array}{l}\text { BASE } \\
\text { INDE- } \\
\text { XADA }\end{array}$ & ANO & OBJETIVO & $\begin{array}{l}\text { TIPO DE } \\
\text { ESTUDO }\end{array}$ & SÍNTESE DO ESTUDO \\
\hline $\begin{array}{l}\text { A vivência da } \\
\text { sexualidade } \\
\text { por idosas } \\
\text { viúvas e suas } \\
\text { percepções } \\
\text { quanto à } \\
\text { opinião dos } \\
\text { familiares a } \\
\text { respeito }\end{array}$ & 帒 & $\stackrel{n}{\infty}$ & $\begin{array}{c}\text { Descrever a } \\
\text { vivência da } \\
\text { sexualidade por } \\
\text { mulheres idosas } \\
\text { viúvas, } \\
\text { frequentadoras de } \\
\text { um Centro de } \\
\text { Convivência do } \\
\text { Idoso, e verificar a } \\
\text { percepção quanto } \\
\text { à opinião dos seus } \\
\text { familiares. }\end{array}$ & $\begin{array}{l}\text { Pesquisa } \\
\text { qualitativa e } \\
\text { exploratório- } \\
\text { descritiva. }\end{array}$ & $\begin{array}{l}\text { O estudo foi coletado por meio de } \\
\text { entrevistas semiestruturadas e } \\
\text { submetido à análise de conteúdo } \\
\text { temática. Emergiram desta as } \\
\text { categorias: A vivência da } \\
\text { sexualidade sofreu algumas } \\
\text { modificações após o estado de } \\
\text { viuvez garantindo submissão às } \\
\text { normas e regras sociais para o } \\
\text { comportamento feminino; as } \\
\text { idosas assumem ter optado pela } \\
\text { vida sem um novo companheiro; a } \\
\text { família apoia o convívio social, } \\
\text { mas não existe declaração de } \\
\text { apoio para novos relacionamentos } \\
\text { amorosos; e houve ressignificação }\end{array}$ \\
\hline
\end{tabular}




\begin{tabular}{|c|c|c|c|c|c|}
\hline & & & & & $\begin{array}{c}\text { das questões de gênero no } \\
\text { tocante às mudanças relativas ao } \\
\text { papel social da mulher, depois da } \\
\text { viuvez. }\end{array}$ \\
\hline $\begin{array}{l}\text { Autoconceito } \\
\text { em idosos } \\
\text { homossexuai } \\
\text { s: um estudo } \\
\text { exploratório }\end{array}$ & 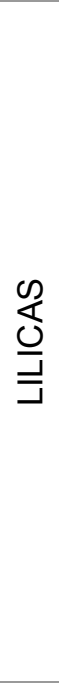 & $\stackrel{n}{\stackrel{2}{N}}$ & $\begin{array}{c}\text { Estudar a velhice } \\
\text { e a } \\
\text { homossexualidade } \\
\text {, no contexto } \\
\text { família e } \\
\text { sociedade. }\end{array}$ & $\begin{array}{l}\text { Trata-se de um } \\
\text { estudo de } \\
\text { caso, trabalho } \\
\text { de caráter } \\
\text { qualitativo, } \\
\text { exploratório. }\end{array}$ & $\begin{array}{l}\text { Dentro da temática da sexualidade, } \\
\text { destaca-se, neste estudo, que a } \\
\text { homossexualidade na velhice, } \\
\text { apesar de ser tema relevante nos } \\
\text { dias atuais, ainda é, porém, pouco } \\
\text { explorado na literatura científica; e } \\
\text { que não se pode estudar a velhice } \\
\text { e a homossexualidade, separando } \\
\text { o indivíduo da sociedade em que } \\
\text { vive ou da família em que está } \\
\text { inserido; dessa forma, deve-se } \\
\text { conhecer o individual e o coletivo } \\
\text { separadamente, para que se possa } \\
\text { realmente compreender esse } \\
\text { aspecto na vida de uma pessoa e } \\
\text { contribuir para um envelhecimento } \\
\text { bem-sucedido. }\end{array}$ \\
\hline $\begin{array}{c}\text { Comportamen } \\
\text { to sexual de } \\
\text { idosos } \\
\text { assistidos na } \\
\text { estratégia } \\
\text { saúde da } \\
\text { família }\end{array}$ & O & $\stackrel{10}{\stackrel{2}{N}}$ & $\begin{array}{c}\text { Analisar o } \\
\text { comportamento } \\
\text { sexual de idosos } \\
\text { assistidos na } \\
\text { atenção primária } \\
\text { em saúde. }\end{array}$ & $\begin{array}{l}\text { Trata-se de um } \\
\text { estudo } \\
\text { transversal, } \\
\text { exploratório e } \\
\text { descritivo, com } \\
\text { abordagem } \\
\text { quantitativa. }\end{array}$ & $\begin{array}{c}\text { Destaca-se que há uma diminuição } \\
\text { gradual na frequência do interesse } \\
\text { e das práticas sexuais com a idade, } \\
\text { reforça-se a necessidade da ação } \\
\text { educativa do enfermeiro na } \\
\text { atenção primária voltada para } \\
\text { idosos. }\end{array}$ \\
\hline $\begin{array}{l}\text { Representaçõ } \\
\text { es sociais da } \\
\text { sexualidade } \\
\text { entre idosos }\end{array}$ & O & $\stackrel{n}{2}$ & $\begin{array}{l}\text { Conhecer a } \\
\text { representação } \\
\text { social sobre } \\
\text { sexualidade de } \\
\text { idosos, com base } \\
\text { na teoria das } \\
\text { representações } \\
\text { sociais. }\end{array}$ & $\begin{array}{l}\text { Pesquisa } \\
\text { descritiva e } \\
\text { exploratória, } \\
\text { amparada na } \\
\text { Teoria das } \\
\text { Representaçõe } \\
\text { s Sociais com } \\
\text { análise } \\
\text { qualitativa. }\end{array}$ & $\begin{array}{l}\text { Estudo feito com } 30 \text { idosos onde os } \\
\text { mesmos evocaram } 150 \text { palavras } \\
\text { associadas ao termo indutor } \\
\text { sexualidade e, destas, } 43 \\
\text { diferentes. No possível núcleo } \\
\text { central da representação dos } \\
\text { idosos sobre sexualidade, foram } \\
\text { encontradas as palavras: amor, } \\
\text { carinho e respeito. Sexo, } \\
\text { companheirismo, compreensão e } \\
\text { convivência compuseram os } \\
\text { elementos intermediários da } \\
\text { representação. }\end{array}$ \\
\hline $\begin{array}{l}\text { Sexualidade } \\
\text { na terceira } \\
\text { idade: } \\
\text { percepção de } \\
\text { homens } \\
\text { idosos de uma } \\
\text { estratégia de } \\
\text { saúde da } \\
\text { família }\end{array}$ & $\begin{array}{l}\text { 岂 } \\
\text { 品 }\end{array}$ & $\stackrel{10}{\stackrel{2}{N}}$ & $\begin{array}{c}\text { Identificar o } \\
\text { conhecimento e os } \\
\text { fatores que } \\
\text { interferem na } \\
\text { sexualidade de } \\
\text { homens idosos. }\end{array}$ & $\begin{array}{l}\text { Estudo } \\
\text { qualitativo. }\end{array}$ & $\begin{array}{l}\text { Estudo feito com os idosos que } \\
\text { relataram ainda ter disposição para } \\
\text { manter relações sexuais. } \\
\text { Demonstram-se satisfeitos com sua } \\
\text { vida sexual, mas sem basear sua } \\
\text { vida conjugal ao sexo propriamente } \\
\text { dito, acreditando fazer seu melhor } \\
\text { para manter a qualidade de vida. } \\
\text { Referiram que os profissionais de } \\
\text { saúde não costumam abordar } \\
\text { aspectos relacionados à } \\
\text { sexualidade e à vida sexual nas } \\
\text { consultas }\end{array}$ \\
\hline
\end{tabular}




\begin{tabular}{|c|c|c|c|c|c|}
\hline $\begin{array}{l}\text { Vovó e vovô } \\
\text { também } \\
\text { amam: } \\
\text { sexualidade } \\
\text { na terceira } \\
\text { idade }\end{array}$ & 盝 & 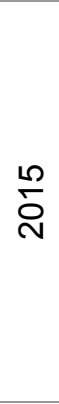 & \begin{tabular}{|} 
Analisar a prática \\
profissional de \\
médicos e \\
enfermeiros da \\
Estratégia Saúde \\
da Família no que \\
se refere aos \\
aspectos da \\
sexualidade em \\
idosos.
\end{tabular} & $\begin{array}{l}\text { Estudo } \\
\text { exploratório, de } \\
\text { abordagem } \\
\text { qualitativa. }\end{array}$ & $\begin{array}{l}\text { O estudo revela o significado } \\
\text { atribuído pelos profissionais à } \\
\text { sexualidade na terceira idade, as } \\
\text { formas como os profissionais } \\
\text { identificam as necessidades } \\
\text { sexuais, como era realizado o } \\
\text { atendimento das necessidades } \\
\text { sexuais de idosos e as ações sobre } \\
\text { a qualidade da vida sexual. }\end{array}$ \\
\hline $\begin{array}{c}\text { Idosos, } \\
\text { infecções } \\
\text { sexualmente } \\
\text { transmissívei } \\
\text { s e aids: } \\
\text { conhecimento } \\
\text { e percepção } \\
\text { de risco }\end{array}$ & 盝 & $\stackrel{\circ}{\circ}$ & $\begin{array}{c}\text { Investigar o } \\
\text { conhecimento e } \\
\text { verificar a } \\
\text { percepção de risco } \\
\text { de idosos quanto à } \\
\text { contaminação por } \\
\text { Infecções } \\
\text { Sexualmente } \\
\text { Transmissíveis } \\
\text { (IST) e HIV. }\end{array}$ & $\begin{array}{l}\text { Trata-se de } \\
\text { estudo } \\
\text { descritivo de } \\
\text { natureza } \\
\text { quantitativa. }\end{array}$ & $\begin{array}{c}\text { Estudo feito com idosos entre } 60 \text { - } \\
70 \text { anos, sexo masculino, casados, } \\
\text { católicos, com o nível fundamental } \\
\text { incompleto. Além disso, } 40 \% \text { dos } \\
\text { idosos citaram o uso do } \\
\text { preservativo como principal método } \\
\text { de prevenção às infecções sexuais, } \\
21,9 \% \text { responderam que o HIV é } \\
\text { transmitido de uma pessoa para } \\
\text { outra por meio do contato sexual e } \\
38,2 \% \text { citaram que a doença não } \\
\text { tem cura. Sobre a percepção de } \\
\text { risco, } 76,4 \% \text { referiram que não } \\
\text { tinham nenhuma possibilidade de } \\
\text { adquirir Infecções Sexualmente } \\
\text { Transmissíveis ou HIV. }\end{array}$ \\
\hline $\begin{array}{c}\text { Cuidado } \\
\text { terapêutico de } \\
\text { enfermagem: } \\
\text { transições da } \\
\text { sexualidade } \\
\text { do cônjuge- } \\
\text { cuidador do } \\
\text { idoso }\end{array}$ & $\begin{array}{l}0 \\
ٍ \\
ٍ\end{array}$ & $\stackrel{N}{\circ}$ & $\begin{array}{l}\text { Compreender as } \\
\text { transições } \\
\text { vivenciadas, suas } \\
\text { condições e os } \\
\text { padrões de } \\
\text { resposta } \\
\text { esperados a } \\
\text { mudanças na } \\
\text { sexualidade do } \\
\text { cônjuge-cuidador } \\
\text { do idoso em } \\
\text { processo } \\
\text { demencial. }\end{array}$ & $\begin{array}{l}\text { Abordagem } \\
\text { qualitativa }\end{array}$ & $\begin{array}{l}\text { Pode-se compreender com esse } \\
\text { estudo a construção de vida } \\
\text { familiar e conjugal; os aspectos de } \\
\text { formação e desenvolvimento da } \\
\text { sexualidade; as especificidades } \\
\text { que envolvem viver e cuidar do } \\
\text { outro, com sucessivos } \\
\text { acontecimentos e mudanças } \\
\text { influenciados pela velhice, por } \\
\text { processo demencial, crenças e } \\
\text { imaginário social. }\end{array}$ \\
\hline $\begin{array}{c}\text { Vivência da } \\
\text { sexualidade } \\
\text { por mulheres } \\
\text { idosas }\end{array}$ & 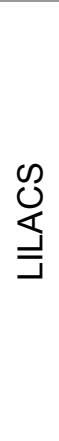 & $\hat{\circ}$ & $\begin{array}{l}\text { Interpretar a } \\
\text { vivência da } \\
\text { sexualidade pela } \\
\text { mulher idosa e } \\
\text { construir um } \\
\text { modelo teórico } \\
\text { explicativo. }\end{array}$ & $\begin{array}{c}\text { Estudo } \\
\text { qualitativo por } \\
\text { meio da teoria } \\
\text { fundamentada } \\
\text { nos dados. }\end{array}$ & $\begin{array}{l}\text { Nesse estudo elaboraram-se as } \\
\text { categorias: percebendo } \\
\text { modificações do próprio } \\
\text { envelhecimento e o do } \\
\text { companheiro; ponderando que a } \\
\text { sexualidade se mantém com o } \\
\text { envelhecimento; apresentando } \\
\text { dificuldades sociais e culturais na } \\
\text { vivência da sexualidade; buscando } \\
\text { alternativas para adaptar a vivência } \\
\text { da sexualidade. }\end{array}$ \\
\hline
\end{tabular}




\begin{tabular}{|c|c|c|c|c|c|}
\hline $\begin{array}{c}\text { Atuação da } \\
\text { equipe de } \\
\text { enfermagem } \\
\text { frente à } \\
\text { sexualidade } \\
\text { de idosas } \\
\text { institucionaliz } \\
\text { adas }\end{array}$ & 导 & $\stackrel{\infty}{\stackrel{\infty}{\sim}}$ & $\begin{array}{c}\text { Analisar o } \\
\text { desempenho da } \\
\text { equipe de } \\
\text { enfermagem frente } \\
\text { à sexualidade no } \\
\text { cotidiano de } \\
\text { idosas } \\
\text { institucionalizadas. }\end{array}$ & \begin{tabular}{|c|} 
Este estudo \\
corresponde ao \\
recorte de uma \\
dissertação de \\
mestrado que \\
se utilizou de \\
abordagem \\
qualitativa e \\
descritiva. \\
\end{tabular} & $\begin{array}{l}\text { Estudo feito com profissionais de } \\
\text { enfermagem. Formações } \\
\text { ideológicas e imaginárias } \\
\text { permeiam o discurso dos sujeitos, } \\
\text { evocando a compreensão da } \\
\text { sexualidade, sua conformação } \\
\text { institucional e o desempenho } \\
\text { exigido nas manifestações dessa } \\
\text { sexualidade. Assim, considerando } \\
\text { o desempenho dos profissionais, } \\
\text { tornou-se possível identificar } \\
\text { dificuldades como constrangimento, } \\
\text { desconforto ou prevalência de } \\
\text { crenças e estratégias pessoais. } \\
\text { Essas estratégias diversificaram-se } \\
\text { desde o uso do humor até ações } \\
\text { repressivas diretas. }\end{array}$ \\
\hline $\begin{array}{c}\text { Sexualidade } \\
\text { de idosos: } \\
\text { conhecimento } \\
\text { latitude de } \\
\text { enfermeiros } \\
\text { da Estratégia } \\
\text { Saúde da } \\
\text { Família }\end{array}$ & 怘 & $\stackrel{\circ}{\stackrel{\sim}{\sim}}$ & $\begin{array}{c}\text { Avaliar o } \\
\text { conhecimento e } \\
\text { atitudes dos } \\
\text { enfermeiros da } \\
\text { Estratégia Saúde } \\
\text { da Família em } \\
\text { relação à } \\
\text { sexualidade na } \\
\text { velhice. }\end{array}$ & $\begin{array}{l}\text { Trata-se de um } \\
\text { estudo de corte } \\
\text { transversal, } \\
\text { exploratório, } \\
\text { descritivo, de } \\
\text { abordagem } \\
\text { quantitativa. }\end{array}$ & $\begin{array}{l}\text { Estudos realizados com } \\
\text { enfermeiros, a maioria mulheres, } \\
\text { jovens adultos, que relataram ter } \\
\text { condições de orientar sobre } \\
\text { sexualidade. Os participantes que } \\
\text { declararam receber educação } \\
\text { permanente em saúde e realizar } \\
\text { educação em saúde sobre } \\
\text { sexualidade apresentaram um } \\
\text { conhecimento significativamente } \\
\text { favorável, mas nenhuma atitude } \\
\text { estatisticamente significativa. }\end{array}$ \\
\hline
\end{tabular}

Fonte: Elaborado pelos autores, 2019.

\section{Sexualidade do idoso no contexto familiar}

O envelhecimento é um processo orgânico inerente à existência humana e traz consigo modificações biológicas, psicossociais e culturais (CUNHA et al., 2015). Contudo, Nascimento et al. (2017), reiteram que embora a senescência seja um processo biológico, cada pessoa envelhece de modo individual e singular, o que implica atenção especial personalizada por parte dos profissionais de saúde aos sujeitos dessa faixa etária.

Entretanto, Souza et al. (2015), expõe que a sexualidade é uma dimensão humana intimamente ligada às necessidades de prazer, intimidade, reprodução, afetividade, amor, autorrealização, autoestima, autoimagem, entre outras. Os autores corroboram que o idoso expressa e vivencia pensamentos, relacionamentos, 
atitudes e crenças, consolidando-se através da interação de diversos fatores, sobretudo os biológicos, psicológicos, sociais, econômicos, culturais, religiosos e históricos.

Para Pereira et al. (2015), não há uma teoria que determine como se deve envelhecer. Na realidade pode-se observar que se envelhece como se vive ao longo da vida, o que faz refletir sobre o processo de envelhecimento subjetivo, individual, porém construído com influências do contexto social, cultural, religioso e familiar. Nascimento et al. (2017), no processo de envelhecimento, importantes repercussões, as quais as tornam uma temática revestida por preconceitos e atitudes sociais que dificultam sua manifestação por parte da população.

Lima et al. (2017) entendem que a família é o pilar de apoio, ou seja, a primeira unidade social de inserção e instituição que contribui para o desenvolvimento e a socialização. Em depoimentos, os estudos revelaram que as relações familiares giravam em torno de conflitos, impedimentos ou disponibilidade restrita de familiares para o cuidado ao idoso. Quanto à sexualidade, o diálogo e a educação sexual foram considerados falhos Luz et al. (2015) explica que os familiares devem apoiar aos idosos quando os mesmos decidirem optar por uma vida a dois mesmo depois da terceira idade e não criticar e/ou reprimir como acontece quando os mesmos exprimem qualquer forma de sexualidade. Peixer at al. (2015), é possível evidenciar que os homens idosos entendem que a sexualidade faz parte da vida como uma necessidade humana, alívio para as tensões e, principalmente, como sinônimo do próprio ato sexual.

Com esta percepção, Luz et al. (2015) corroboram que os idosos sentem desejo sexual e quando existe oportunidade mantêm relações sexuais. No entanto, a sociedade impõe que os indivíduos de idade avançada não necessitam de sexo, com isso muitos idosos abdicam do seu prazer para não serem lançados à margem da sociedade.

Caber ressaltar que os organismos governamentais e não governamentais devem investir em práticas educativas, às quais os idosos podem ser inseridos em ambiente que abordem a temática de forma aberta, livre de preconceitos e estígmas, partindo essencialmente do reconhecimento da sexualidade, proporcionando maior segurança e qualidade de vida para o ser (BRITO et al., 2016). 


\section{Atuação do enfermeiro no processo de sexualidade do idoso no contexto familiar}

Lima et al. (2017) conscientiza acerca da abordagem do profissional enfermeiro sobre a sexualidade que depende do nível de preparo e conhecimento/habilidade, pois as mudanças da prática cotidiana exigem entendimentos para tomada de decisões e habilidades na nova circunstância de vida. Portanto, o padrão de resposta esperado é estar apto, como profissional de saúde, a identificar e abordar questões da sexualidade.

Os estudos mostram que a sexualidade na terceira idade ainda é um tema restrito e, muitas vezes, esquecido por profissionais da saúde e até mesmo pela sociedade e família, construindo o imaginário de idosos como seres assexuados (QUEIROZ et al., 2015). Para Evangelista et al. (2019), o contato longitudinal do enfermeiro da atenção primária junto ao idoso promove uma relação forte, pautada na confiança mútua, que pode facilitar e estimular a expressão de necessidades íntimas, como aquelas relacionadas à sexualidade. Assim, o enfermeiro tem que estar apto para avaliar, ter conhecimento e atitude na Estratégia Saúde da Família sobre sexualidade na velhice.

Para Luiz et al. (2015) é importante que o enfermeiro aborde questões da sexualidade com idosos, permitindo um espaço para que os mesmos sintam confiança e possam adquirir conhecimentos, tirar dúvidas, rompendo mitos e tabus, respeitar a vontade dos seres humanos e deixá-los viver livres, também, para uma vida sexual, sem preconceito.

Cunha et al. (2015) expressam que profissional de enfermagem necessitam desenvolver estratégias pautadas no vínculo e na interação entre profissional/usuário. Com essa interação, poderia haver a superação dos constrangimentos causados quando se fala sobre sexualidade com idosos. Para que os profissionais consigam atender de forma integral e equânime à saúde do idoso, precisam estar capacitados para isso. 
De acordo com os estudos Peixer at al. (2015), abordar o tema sexualidade com os idosos, é importante que o profissional de saúde aborde também questões ligadas ao planejamento familiar, de uma forma mais integral e não se limitando apenas às questões biologicistas.

A enfermagem conjectura inúmeras possibilidades de atuação nesse contexto, destarte, depreende-se que, para compreender e atuar sobre aspectos da sexualidade, não basta conhecer a anatomia e a fisiologia sexuais, mas é também necessário levar em consideração os aspectos psicossociais e culturais em que os indivíduos estão inseridos (VENTURINI et al., 2018).

Para Evangelista et al. (2019), os profissionais enfermeiro(a) devem ser isentos de preconceitos, e é essencial que não tratem o idoso como um ser em degeneração. Logo, deve criar situações de valorização da autoestima, falar diretamente sobre o assunto, responder a todos os questionamentos, sem rodeios ou constrangimentos, auxiliando no bem-estar biopsicossocial, e no contexto familiar.

Lima et al. (2017) defendem que o cuidado terapêutico de enfermagem deve firmar-se em bases teóricas, a fim de respaldar que todas as possibilidades sejam dimensionadas e conduzidas para a conexão, interação, envolvimento, confiança e enfrentamento de transições por parte dos indivíduos que as vivenciam, instrumentalizando o trabalho de enfermagem.

Para entender o idoso e o que envolve a sua sexualidade, é necessário levar em consideração sua conduta sexual determinada pelo contexto biopsicossocial. Deste modo, o cuidado da enfermagem nos princípios da humanização, aliando o 13 cuidado técnico ao cuidado emocional, minimiza os problemas que interferem na relação enfermeiro, idoso e a família. Permite, ainda, aos profissionais lidar com as limitações e conflitos de uma forma mais saudável, respeitando valores e concepções do idoso.

Assim, a enfermagem deve reconhecer sua importância como educadora e agente de transformação social, sendo uma constante em sua atuação profissional, visto que a educação permanente em saúde do idoso deve ser parte integrante de seu escopo profissional. Entretanto, o enfermeiro deve refletir de forma consciente sobre suas ações e atitudes no cuidado com o idoso, no sentido de possibilitar o 
desenvolvimento de práticas holísticas, reflexivas e capazes de subsidiar a assistência humanizada.

\section{CONCLUSÃO}

Para entender o idoso e o que envolve a sua sexualidade, é necessário levar em consideração sua conduta sexual determinada pelo contexto biopsicossocial. Deste modo, o cuidado da enfermagem nos princípios da humanização, aliando o cuidado técnico ao cuidado emocional, minimiza os problemas que interferem na relação enfermeiro, idoso e a família. Permite, ainda, aos profissionais lidar com as limitações e conflitos de uma forma mais saudável, respeitando valores e concepções do idoso.

Assim, a enfermagem deve reconhecer sua importância como educadora e agente de transformação social, sendo uma constante em sua atuação profissional, visto que a educação permanente em saúde do idoso deve ser parte integrante de seu escopo profissional. Entretanto, o enfermeiro deve refletir de forma consciente sobre suas ações e atitudes no cuidado com o idoso, no sentido de possibilitar o desenvolvimento de práticas holísticas, reflexivas e capazes de subsidiar a assistência do cuidador. 


\section{REFERÊNCIAS BIBLIOGRÁFICAS}

ARAUJO, A.S. et al. Atuação do enfermeiro na assistência ao pré-natal versus sífilis: uma revisão integrativa. Interfaces Científicas - Saúde e Ambiente, Aracaju, 2018; v. 6, n. 2, p.95110. Disponível em:< https://periodicos.set.edu.br/index.php/saude/article/view/4626/pdf>, acessado em 09 de agosto de 2019.

BRITO, N. M. I.; et al. Idosos, infecções sexualmente transmissíveis e aids: conhecimentos e percepção de risco. ABCS Health Sciences, vol. 41, núm. 3, 2016, p. 140-145. Disponível em: < https://www.portalnepas.org.br/abcshs/article/view/902 >, acessado em 20 de agosto de 2019.

CUNHA, L. M.; et al. Vovó e vovô também amam: sexualidade na terceira idade. Revista Min Enfermagem, vol. 19, núm. 4, out-dez, 2015, pp. 894-900. Disponível em: < file:///C:/Users/Julia/Downloads/v19n4a08.pdf >, acessado em 18 de agosto de 2019.

EVANGELISTA, A. R.; et al. Sexualidade de idosos: conhecimento/atitude de enfermeiros da Estratégia Saúde da Família. Revista da Escola de Enfermagem da USP, vol. 53, São paulo, 2019, p. 1-8. Disponível em: < http://www.scielo.br/pdf/reeusp/v53/1980- 220X-reeusp-53e03482.pdf > acessado em 22 de agosto de 2019.

FERRO A. P.; et al. Perfil da síndrome da imunodeficiência adquirida em idosos. Rev. iberoam. educ. investi. Enferm, vol. 6, núm. 1, 2019, p.49-55. Disponível em < http://www.scielo.br/scielo.php?script=sci_arttext\&pid=S0103-21002012000200023 >, acessado em 08 de agosto de 2019.

GONÇALVES, C. D. Envelhecimento bem-sucedido, envelhecimento produtivo e envelhecimento ativo: reflexões. Rev. Estudos Interdisciplinares Sobre o Envelhecimento, vol. 20, núm. 2, 2015, p. 645-657. Disponível em: < https://seer.ufrgs.br/RevEnvelhecer/article/view/49428 >, acessado em 08 de agosto de 2019.

LIMA, C. F. M.; et al. Cuidado terapêutico de enfermagem: transições da sexualidade do cônjuge-cuidador do idoso. Rev Bras Enferm, vol. 70, núm. 4, jul-ago, 2017, p. 705-713. Disponivel em: < http://www.scielo.br/pdf/reben/v70n4/pt_0034-7167-reben-70-04- 0673.pdf >, acessado em 26 de agosto de 2019.

LUIZ, A. C. G.; et al. Comportamento sexual de idosos assistidos na estratégia saúde da família. Revista de Pesquisa Cuidado é fundamental Online, vol. 7, núm. 2, abr-jun, 2015, p. 2229-2240. Disponível em:

em: http://www.seer.unirio.br/index.php/cuidadofundamental/article/view/3580 > acessado em 15 de agosto de 2019.

MARQUES, A. D. B.; et al. A vivência da sexualidade de idosos em um centro de convivência. Rev. Enferm. Cent. O. Min, vol. 5, núm. 3, set-dez, 2015, pp. 1768-1783. Disponível em: < http://www.seer.ufsj.edu.br/index.php/recom/article/view/913/930 >, acessado em 07 de agosto de 2019.

MEDEIROS, M. A. D.; PAIXÃO, M.C.; MIRANDA, L.N. Atenção multidisciplinar através do Consultório na Rua. Ciências Biológicas e de Saúde Unit, Alagoas, 2017; v. 4, n. 2, p.283296.

https://periodicos.set.edu.br/index.php/fitsbiosaude/article/view/4558/2622>, acessado em 09 de agosto de 2019.

MIRANDA, A. C. C.; et al. Avaliação da presença de cuidador familiar de idosos com déficits cognitivo e funcional residentes em Belo Horizonte-MG. Rev. bras. geriatria gerontologia, vol.18, núm.1, jan-mar, 2015, p. 141-150. Disponível em: < http://www.scielo.br/scielo.php?script=sci_arttext\&pid=S1809- 
98232015000100141\&lng=pt\&tlng=pt >, acessado em 07 de agosto de 2019.

MOCELIN, C.; et al. O cuidado do idoso dependente no contexto familiar. Revista Online de Pesquisa, vol. 09, núm. 4, 2017, p. 1034-1039. Disponível em: < http://www.seer.unirio.br/index.php/cuidadofundamental/article/view/5747/pdf_1>, acessado em 08 de agosto de 2019.

NASCIMENTO, R. N.; et al. Vivência da sexualidade por mulheres idosas. Revista Enfermagem Uerj, vol. 25, Rio de Janeiro, 2017, p. 1-5. Disponível em: < https://www.epublicacoes.uerj.br/index.php/enfermagemuerj/article/view/20892 >, acessado em 28 de agosto de 2019.

PEIXER, T. C.; et al. Sexualidade na terceira idade: percepção de homens idosos de uma estratégia de saúde da família. Journal of Nursing and Health, vol. 5, núm. 2, 2015, p. 131140.

Disponível em:

https://periodicos.ufpel.edu.br/ojs2/index.php/enfermagem/article/view/4681/4603 > acessado em 17 de agosto de 2019.

PEREIRA, K. C. S. A.; et al. Auto conceito em idosos homossexuais: um estudo exploratório. Revista Kairós Gerontologia, vol. 18, núm. 1, São Paulo, 2015, p. 259-275. Disponível em: < https://revistas.pucsp.br/index.php/kairos/article/view/26062 > acessado em 12 de agosto de 2019.

QUEIROZ, M. A. C.; et al. Representações sociais da sexualidade entre idosos. Revista Brasileira de Enfermagem, vol. 68, núm. 4, jul-ago, Brasília, 2015, p. 662-667. Disponível em: < http://www.scielo.br/pdf/reben/v68n4/0034-7167-reben-68-04-0662.pdf > acessado em 15 de agosto de 2019.

ROMERO, D. E.; et al. Diretrizes e indicadores de acompanhamento das políticas de proteção à saúde da pessoa idosa no Brasil. Revista Eletrônica de Comunicação Informação \& Inovação em Saúde, vol. 13, núm. 1, jan-mar, 2019, p. 134-157. Disponível em: < https://www.reciis.icict.fiocruz.br/index.php/reciis/article/view/1569 >, acessado em 07 de agosto de 2019.

SOUZA, M. T.; SILVA, M. D.; CARVALHO, R. Revisão integrativa: o que é e como fazer. Revista Einstein (São Paulo), vol. 8, núm. 1, jan-marc, 2010, p. 102-2016. Disponível em: < http://www.scielo.br/pdf/eins/v8n1/pt_1679-4508-eins-8-1-0102.pdf > acessado em 09 de agosto de 2019.

SOUZA, M.; et al. A vivência da sexualidade por idosas viúvas e suas percepções quanto à opinião dos familiares a respeito. Revista Saúde e Sociedade, vol. 24, núm. 3, São Paulo, JulSet, 2015, p. 936-944. Disponível em: < http://www.scielo.br/pdf/sausoc/v24n3/0104- 1290sausoc-24-03-00936.pdf > acessado em 11 de agosto de 2019.

VALCARENGHI R. V.; et al. Produção científica da Enfermagem sobre promoção de saúde, condição crônica e envelhecimento, Revista Brasileira de Enfermagem, vol. 68, núm. 4, julago, 2015, $\quad$ p. 705-712. $\quad$ Disponível em < http://www.scielo.br/scielo.php?script=sci_arttext\&pid=S0034-

$71672015000400705 \&$ Ing=pt\&tIng=pt >, acessado em 08 de agosto de 2019.

VENTURINI, L.; et al. Atuação da equipe de enfermagem frente à sexualidade de idosas institucionalizadas. Rev Esc Enferm USP, vol. 52, 2018, pp. 1-8. Disponível em: < http://www.scielo.br/pdf/reeusp/v52/0080-6234-reeusp-S1980-220X2017017903302.pdf >, acessado em 03 de setembro de 2019. 